\title{
The Role of Parasites in Shaping Human ValueS
}

\section{Glenn Weisfeld}

Department of Psychology, Wayne State University, Detroit, MI, USA.

ad4297@wayne.edu

A Review of the Book

\section{The Parasite-Stress Theory of Values and Sociality: Infectious disease, history and human values worldwide}

By Randy Thornhill and Corey L. Fincher. 2014.

Springer, New York, xix +449 pp.

ISBN 978-3-319-08039-0 (hardback \$219.99, USD; paperback \$169.99, USD)

This book presents a synthetic theory of cultural values and history. It expands on a 2012 Behavioral and Brain Sciences target article by the authors, and includes replies to the commentaries. The theory is bold, extensively and rigorously supported, and suitably qualified. This theory needs to be incorporated into analyses of human behavior in a variety of disciplines in the behavioral sciences and history.

The gist of the theory is this: In localities where parasites that transmit disease between humans are abundant, people isolate themselves from outsiders, who may carry infectious diseases. These people tend to fear and avoid outsiders and alien values, and to remain philopatric. This self-imposed isolation favors conservative values because the novel values of outsiders are kept at bay. Parasite stress also reduces innovation and cognitive performance by inducing lethargy; the debilitating effect of parasites may help account for the lower IQ of people living in countries and US states with more parasites. Other ramifications of the theory extend to crime, warfare, endogamy, female chastity, and other behavioral phenomena.

Thornhill and Fincher support their theory by citing numerous studies of a variety of human populations around the world, past and present. They examine a host of variables, and generally provide statistically strong support for their claims. They address 
counterarguments fairly and thoroughly. They acknowledge that theirs is not the only theory to be invoked in explaining human behavior and values, and examine other theories about the effects of parasites on behavior. For example, they cite Low's (1990) correlation between polygyny and parasite stress, the theory being that where parasites thrive women strongly seek disease-free men, even men who are already married. However, many other factors, such as economic inequality between men and a low sex ratio, help explain the prevalence of polygyny. The threat of parasites is one of many selective forces shaping behavior, but one that demands more attention than it has received.

In keeping with the evolutionary approach, the authors provide a functional analysis of human values and history, as contrasted with Great Man historical theories, cyclic theories, economic theories, and theories that posit the existence of disembodied values adhered to for mysterious reasons. That is, the authors trace a variety of human behavioral tendencies to functional emotions such as disgust and fear, specifically of contamination. They regard values as products of individual selection in the sense that values that enhance the bearer's fitness will be favored, and those that reduce fitness will be abandoned. They place little stock in the idea that values will persist indefinitely out of tradition or sentimentality.

The flavor of the book can perhaps be conveyed by citing some examples of supporting evidence; a brief book review cannot do justice to the complexity of the theory. Some of these studies support the idea that exposure to infectious disease sensitizes people to the dangers of contamination. Stevenson et al. (2009) found that individuals with high contamination sensitivity and disgust had fewer recent infectious diseases. Schaller et al. (2010) reported that subjects who were shown slides of people with infectious lesions reacted with a heightened immune response. Thornhill and Fincher propose that exposure to disease activates both the immune system and behavioral prophylactic measures.

The link between parasite stress and endogamy can be explained by noting that exogamous mates may introduce new microbes. Endogamy would also conserve localdisease-fighting gene combinations that are passed on to offspring. In fact, animals and people generally exhibit moderate homogamy, which bolsters fertility, as by reducing miscarriage in people (Rushton, 1988). Isolation of breeding groups, the authors assert, helps explain the panoply of cultural groups and species in warm climates fostering parasites. However, another factor in this diversity of populations is abundance of resources and ecological niches.

The conservative behavior of people exposed to parasite stress is illustrated in multiple ways. Where parasites abound, people travel shorter distances away from home (Cashdan \& Steele, 2013). US supporters of the conservative Republican party tend to have low thresholds for disgust. Racial prejudice was reduced by hygienic measures such as flu vaccination and hand washing. Religious affiliation, which reduces outbreeding, is associated with parasite stress. The emphasis on female chastity that characterizes conservative communities is traced to women's seeking to reassure a suitor that their attraction to disease-free men will be kept in check. However, Vandello and Hastings' (2012) alternative explanation, that chastity offers protection against sexually transmitted diseases, is more parsimonious. Conservatives' aversion to new ideas is consistent with philopatry; the Texas school board has prohibited the teaching of critical 
thinking skills. US conservatives' opposition to welfare programs can perhaps be understood by recognizing that these benefits are generally perceived as going to outsiders, particularly minorities.

The book implicitly calls for a historical science that gives full weight to various emotions that shape the behavior and cognitions of the members of a population. This theory may appeal particularly to those of us who see emotions as the primary drivers of voluntary behavior. These emotions, or motives, might include, in addition to disgust at potential contaminating agents, the seeking of food, water, and moderate temperatures; sexual attraction and aversion; nurturance and protection of mates and kin; and avoidance of the painful consequences of natural disasters and warfare. Such theories might help to bridge the chasm between the sciences and the humanities, and mitigate the skepticism of many in the humanities toward the sciences, and particularly toward evolutionary analyses of human behavior.

This lengthy volume is very clear and well written, and free of typos. There is a subject index but no author index. The book is expensive.

This is an important addition to many fields of knowledge. Scholars will find reading it challenging but eminently worthwhile.

\section{ABOUT THE AUTHOR}

Glenn Weisfeld is a Professor for the Department of Psychology at Wayne State University. He has published widely with recent books including 'The Psychology of Marriage: an evolutionary and cross-cultural view' (coedited with Carol C. Weisfeld and L. M. Dillon) and 'Evolved Emotions: An interdisciplinary and functional analysis'.

\section{REFERENCES}

Cashdan, E., \& Steele, M. (2013). Pathogen prevalence, group bias, and collectivism in the standard cross-cultural sample. Human Nature, 24(1), 59-75. DOI

Fincher, C. L., \& Thornhill, R. (2012). Parasite-stress promotes in-group assortative sociality: The cases of strong family ties and heightened religiosity. Behavioral and Brain Sciences, 35(2), 61-79. DOI

Low, B. S. (1990). Why sex matters: A Darwinian look at human behavior. Princeton, NJ: Princeton University Press. DOI

Rushton, J. P. (1988). Genetic similarity, mate choice, and fecundity in humans. Ethology and Sociobiology, 9(6), 329-333. DOI

Schaller, M., et al. (2010). Mere visual perception of other people's disease symptoms facilitates a more aggressive immune response. Psychological Science, 21(5), 649-652. DOI

Stevenson, R. J., Case, T. I., \& Oaten, M. J. (2009) Frequency and recency of infection and their relationship with disgust and contamination sensitivity. Evolution and Human Behavior, 30(5), 363-368. DOI

Vandello, J. A., \& Hettinger, V. E. (2012). Parasite-stress, cultures of honor, and the emergence of gender bias in purity norms. Behavioral and Brain Science, 35(2), 95-96. DOI 